\title{
AVANCES DEL MODELO DE URBANISMO COLOMBIANO: UNA MIRADA RETROSPECTIVA AL ANÁLISIS DE SU ESTRUCTURA PLANTEADO POR JAVIER GARCIA BELLIDO EN 1998.
}

\author{
Augusto Cesar Pinto Carrillo ${ }^{1}$ \\ Arquitecto.
}

Remisión Artículo: 28-05-08

Palabras clave: planeamiento urbanístico, planes parciales, plusvalías.

Resumen: Con la oportunidad que brinda la Revista ACE a través de la presente publicación de realizar un balance sobre el proceso de implementación en Colombia de la Ley 388 de 1997, o Ley de Desarrollo Territorial - LDT, y consecuentemente de la aplicación de instrumentos de planeamiento urbanístico general y derivado, el presente artículo revive en parte la crítica y recomendaciones que realizara el Arquitecto Javier García-Bellido en su artículo "Perspectivas del nuevo urbanismo colombiano: un análisis de su estructura", publicado en la Revista Desarrollo Urbano en Cifras del Ministerio de Desarrollo Económico (1998). Metodológicamente, se realizó una lectura pormenorizada al artículo, seleccionando principalmente los temas, críticas y recomendaciones que se planteaban con el fin de alimentar la reflexión nacional sobre la aplicación de la LDT; desarrollándose a continuación comentarios sobre su incorporación y avance en la implementación de la Ley y de sus instrumentos.

\section{Introducción.}

La década de los 90 representó para Colombia un salto de gran magnitud en lo relacionado con la producción de normas y políticas urbanas que de manera directa promueven la mejora de las ciudades en términos de planificación y ordenamiento territorial; como también, en la introducción de nuevos instrumentos a través de los cuales se busca garantizar una efectiva gestión del suelo, la participación de los propietarios del mismo en la gestión del urbanismo, la vinculación de capitales privados en programas y proyectos asociados con el desarrollo urbano, y especialmente, cumplir con los derechos y deberes definidos por la Constitución Política de Colombia de 1991, con el fin de garantizar: el derecho de propiedad y la función social y ecológica de la misma, el acceso a una vivienda digna, la libre asociación, la recreación y el deporte, el ambiente sano, entre otros.

Particularmente, el proceso previo de formulación de la LDT demandó la participación de múltiples actores locales e internacionales bajo la orientación del equipo técnico del Ministerio de Desarrollo Económico - Viceministerio de Vivienda, Desarrollo Urbano y Agua Potable, entidad del Estado colombiano competente para la formulación y ejecución de la política urbana nacional. Dentro del equipo de expertos internacionales que acompañó dicho proceso se contó con la asesoría de funcionarios de la Comunidad de Madrid (1994-1995), según lo confirma el mismo García-Bellido en su artículo.

Desde entonces, la semblanza de la LDT con las leyes españolas del suelo es más evidente, mucho más evidente que en la anterior Ley $9^{a}$ de 1989, de la Reforma Urbana, lo cual quedó expresado de la siguiente manera por García-Bellido: "buena parte de la estructura sobre la que descansa la nueva Ley 388 de 1997 tiene un enfoque análogo al de la legislación española

\footnotetext{
${ }^{1}$ Master en Gestión Urbanística de la Universidad Politécnica de Cataluña - Barcelona (2004), Master en Gestión Ambiental para el Desarrollo Sostenible de la Pontificia Universidad Javeriana - Bogotá (1998). Cargo actual: Subdirector de Vivienda y Desarrollo Urbano del Departamento Nacional de Planeación de Colombia, acpinto@dnp.gov.co
} 
del periodo 1956-95, pero con muy positivas correcciones y adiciones introducidas por el Gobierno colombiano (García-Bellido, 1998, p 122)". Tanto este antecedente, como su interés intelectual por estos temas, le llevó a estudiar en detalle cada capítulo de la Ley, como también algunos documentos sobre el urbanismo colombiano. Como resultado, escribió el artículo al que se hace mención en adelante, el cual se anticipó a muchas de las situaciones que actualmente viene enfrentando el proceso de implementación de los instrumentos de planeamiento urbanístico general y de detalle en Colombia.

\section{Aciertos y desaciertos del análisis de García-Bellido sobre la estructura del nuevo urbanismo colombiano.}

Efectivamente, la necesidad generada en Colombia en torno a transformar, construir o hacer ciudad, que comparten algunos países de la Región, es también de índole universal. No obstante, la respuesta a cada problemática debe ser particular, así resulte necesaria la transferencia de técnicas de otros países que evidencian avances y éxito en la implementación de sus estructuras o modelos urbanísticos. Al respecto, y con gran acierto, García-Bellido planteó que "las estructuras de los procesos de producción y transformación social del espacio son cuestión muy distinta, virtualmente incopiables, intransferibles, pertenecen al acervo cultural y social específicamente urdido por cada pueblo o país y a su entera historia acumulada: a lo sumo ciertas estructuras superficiales podrán ser lentamente inoculadas por procesos de difusión, convergencia y transformación, en todo caso, durante generaciones. Porque su estructura profunda subyace en las formas de organización socio-política y jurídica de cada cultura (García-Bellido, 1998, p 119)".

De tal forma, el proceso de implementación de la LDT y de sus instrumentos de planeamiento y gestión del suelo encontraron en las estructuras superficiales existentes hasta entonces en Colombia un primer gran obstáculo. Algunos aspectos que corroboran lo anterior son los siguientes:

- Desde el punto de vista de la organización jurídica, se define una ley que pretende organizar un sistema de planeamiento con instrumentos de escala general y parcial, vinculantes entre sí, que garanticen la función social y ecológica de la propiedad.

- La nueva ley no solo pretende salvaguardar los derechos de los propietarios del suelo, sino también, establece que a los mismos le son inherentes deberes, particularmente la cesión de suelo (en dinero o especie), a través de los cuales se complemente la función pública del urbanismo.

- Tradicionalmente las ciudades se desarrollaron predio a predio, al antojo de los urbanizadores formales e informales, y por lo tanto sin cumplir y/o generar estándares deseables de desarrollo urbano (espacio público, vías, equipamientos, etc.). El nuevo esquema de planeamiento propone un cambio estructural en la forma de "construir ciudad", basado en la gestión asociada del suelo (propietarios, urbanizadores, Estado, entre otros) y soportado sobre el principio universal del reparto equitativo de cargas y beneficios: "todos ponen - todos ganan".

- El interés particular, manifestado en una suma de derechos ilimitados e inquebrantables de la propiedad del suelo, siempre prevaleció ante el interés general.

- Los instrumentos de planeamiento existentes solo se aplicaban en un número de reducido de ciudades, especialmente las de mayor tamaño, y se enfocaban hacia aspectos como la zonificación y regulación de los usos del suelo y el establecimiento de aprovechamientos urbanísticos (alturas y metros cuadrados edificables).

- Los ejercicios de planificación urbana (formulación de los planes de urbanismo y su ejecución) eran desarrollados por las oficinas de planeación, o las que hicieran sus veces, en cada municipalidad. En ningún momento se consultaba a la comunidad y demás interesados en las decisiones y definiciones que se llevaran a cabo por los mismos. 
- Desde el punto de vista socio-político, las decisiones relacionadas con la planificación urbana dependían únicamente de los Consejos Municipales, quienes cumpliendo funciones establecidas por la Constitución Política adoptaban la clasificación y usos del suelo, como también, la delimitación de los perímetros urbanos.

- La práctica de ampliación de los perímetros urbanos, por cuestiones de índole particular y favorecimiento político, predominó ante parámetros técnicos de planeamiento asociados con la demanda real de suelo urbanizable para cubrir el déficit de vivienda, especialmente la de interés social; o por ejemplo, la necesidad de generar suelo para la dotación de espacios y equipamientos públicos, o la consolidación de sistemas de movilidad y ecológicos.

- La ganancia ocasional o plusvalía generada por la incorporación de suelos rurales a urbanos, siempre permaneció en poder de pocos propietarios del suelo que convirtieron en un gran negocio su localización en proximidad a los perímetros urbanos.

- En términos generales, las comunidades asumieron un papel pasivo en cuanto a las normas urbanísticas generadas por las instancias políticas que, en gran medida, limitaban sin mayor justificación sus derechos de propiedad y el patrimonio producido por las rentas del suelo y del mercado inmobiliario.

Tal vez, y sobre el reto de la implementación de una nueva estructura urbanística en Colombia, lo que ha costado más trabajo es transformar la cultura y la forma tradicional de pensar la ciudad y su planeamiento por parte de las instancias políticas, para lo cual se recomendó "someterlas a una limpieza metódica, reinventarlas, reapropiárselas, hacerlas penetrar en el contexto de legitimación de la cultura receptora, lo cual implica un cambio en dicha estructura socio-política para adaptar/adoptar la innovación (García-Bellido, 1998, p 122) ".

Por lo expuesto anteriormente, la LDT y la nueva estructura urbanística en Colombia se fundaron sobre un "paradigma urbanístico holista", consiente fundamentalmente de la necesidad de forjar objetivos colectivos y la construcción del espacio social de todos. GarcíaBellido recomendó también "caminar con paso largo y sostenido por la práctica de la senda técnico-política, operativa y concreta, formulando proposiciones de trazo fino sobre lo que pueda perfilarse y perfeccionarse para el desarrollo de los que dichas leyes, como es lógico, han diseñado como trazo grueso (García-Bellido, 1998, p 122)". Cuando planteó tal recomendación en 1998, se habían expedido apenas dos decretos reglamentarios de la Ley. Diez años después, son más de treinta los que están soportando dicha estructura.

Pese a los pasos largos que se han dado en los primeros diez años de implementación de la Ley, en lo que corresponde a la organización jurídica de la estructura, se mantiene vigente la necesidad de "crear la cultura urbanística necesaria y suficiente para que este salto sea irreversible (García-Bellido, 1998, p 122)". Lo anterior es importante por ejemplo para evitar que en tan poco tiempo de expedida la Ley se ponga en tela de juicio la pertinencia de instrumentos como los planes parciales, los cuales como instrumentos de planeamiento han demostrado su efectividad en otros países donde, con mucho más tiempo, se han logrado perfeccionar y ajustar a las dinámicas sociales y culturales. Por el contrario, dichos instrumentos requieren más bien de un redimensionamiento basado en la disminución de trámites y tiempos requeridos actualmente para su concertación y aprobación.

Al respecto, lo que las instancias técnico-políticas no deben permitir es la acomodación nuevamente de las reglas de juego impartidas por la Ley al beneficio particular. De tal forma, los encargados de desarrollar las normas y las políticas asociadas con la planificación urbana, deben terminar de construir y mejorar los instrumentos y procedimientos garantizando los menores costos y tiempos para su ejecución.

\subsection{Sobre los principios rectores modelo urbanístico colombiano.}


Así mismo, y como también lo señala la historia del urbanismo español según García-Bellido, culturalmente el nuevo modelo impuesto en Colombia se ve obligado a romper con algunos paradigmas político-ideológicos asociados, tiempo atrás, a la propiedad fundiaria: tender a no cargarle tributos, no gravarle con deudas, no expropiarle, otorgarle a todos lo mismo con el mismo plan o favorecer individualmente a los propietarios del suelo frente al sector industrial de la construcción.

Para lograr lo anterior, es probable que se hayan planteado en la LDT principios como el reparto equitativo de cargas y beneficios entre propietarios del suelo, y la función social de la propiedad. Al respecto, es importante que nos sigamos haciendo la pregunta ¿a quién beneficia el plan y en qué le beneficia? Pues bien, si en primera instancia los beneficiarios son "los propietarios del suelo gracias al plusvalor creado por los planes; que sean ellos también los que entreguen gratuitamente a cambio, como justa contraprestación a la colectividad, los terrenos necesarios para los usos y obras públicas (García-Bellido, 1998, p 127)".

Por otro lado, es importante terminar de delimitar los parámetros de equidad entre los beneficiarios, no solo en términos de las ganancias económicas, en función de los aprovechamientos urbanísticos generados por el plan, sino también en función de la distribución de los deberes o cargas impuestos por el mismo. En la estructura del urbanismo español el reparto equitativo de los valores, deberes y derechos se lleva a acabo mediante la técnica de la reparcelación. En Colombia, pese a que la Ley establece la figura del reajuste de terrenos para efectos de cumplir con el mismo propósito, es en términos generales a través del Plan Parcial y de las Unidades de Actuación Urbanística - UAU, en las cuales se está concretando esta práctica jurídico-económica.

Mientras tanto, la expectativa que plantea García-Bellido en su ejercicio comparativo entre los urbanismos colombiano y español, en referencia a que los propietarios del suelo se conviertan en empresarios-urbanizadores asociados forzosos para cada UAU, en el caso colombiano y de lo observado en algunos planes parciales adoptados en ciudades del país, se mantiene la práctica de que el empresario urbanizador compra directamente el suelo y desarrolla el plan parcial, y por el contrario ninguno de los propietarios iniciales participa como socio en la operación.

La "gestión asociada" por desarrollar a través de mecanismos como el reajuste de terrenos o la cooperación entre partícipes, se ha limitado en muy pocos casos a simples ejercicios de integración inmobiliaria entre los socios capitalistas, compradores y propietarios finales del suelo. Sobre tales parámetros vale la pena mantener en cuestión la pertinencia de un mecanismo como el reajuste de terrenos (así lo hemos interpretado desde la experiencia española con las reparcelaciones y la japonesa con el kukaku seiri o reajuste de terrenos), habiéndosele antepuesto la función del reparto equitativo de las cargas y beneficios al Plan Parcial y las UAU, figuras a las que quedó atado jurídicamente.

De tal forma, la expectativa planteada por García-Bellido en cuanto a que con el nuevo modelo en Colombia se evitaría la cruda dependencia y el protagonismo otorgado a los propietarios del suelo (casi monopólica), por lo pronto si se observa que la clase terrateniente es dominante frente al empresariado industrial (constructores), y la participación del pequeño propietario del suelo es muy limitada: "Debe estarse muy atento a esta evolución en los próximos años, y la mejor vía es la de dejar muy claros desde el comienzo los conceptos jurídico-económicos fundamentales de los "derechos otorgados" y las "plusvalías generadas" por el plan, así como los de "participación" de la colectividad en las mismas, temas centrales también en el modelo colombiano (García-Bellido, 1998, p 129 - 130)".

\subsection{Acerca del Plan de Ordenamiento Territorial - POT y las clases de suelo.}


Efectivamente, la universalización de los POT en todos los municipios del país conllevó a la unificación de criterios de planeamiento urbano, la estandarización de formas de gestión del suelo determinadas por la LDT (a la fecha 1.088 de los 1.101 municipios tienen el POT adoptado) y la clasificación del suelo municipal (urbano, de expansión urbana y rural). No obstante, las expectativas sobre la articulación de los procesos de escala municipal con los de carácter supramunicipal (departamental y metropolitano) quedaron rezagadas en la medida que fue derogado el artículo $7^{\circ}$ de la Ley que le establecía competencias a las instancias encargadas de dicho planeamiento (gobernaciones departamentales y áreas metropolitanas).

Para efectos de complementar el ordenamiento general determinado por el POT (zonificación de grandes usos y destinos potenciales futuros), los Planes Parciales concretan la planificación de detalle con usos específicos, edificabilidades y afecciones por áreas de cesión. Podría afirmarse que en los primeros 10 años de implementación de la LDT el proceso y los esfuerzos se concentraron en la formulación de los POT y particularmente en el levantamiento de la información que requería dicho ejercicio: cartografía, estudios ambientales y de riesgos, censos socio-económicos, inventarios patrimoniales (arquitectónico y urbanístico), entre otros. Pese a que algunos municipios ya han llevado a cabo revisiones y ajustes de sus POT según lo ordena la Ley ${ }^{2}$, no ha sido significativo durante los primeros 10 años de expedida la Ley el avance del planeamiento derivado, como se observa en la Tabla 1.

\footnotetext{
${ }^{2}$ Ministerio de Ambiente, Vivienda y Desarrollo Territorial. Ley 388 de 1997, Artículo 28, Vigencia y Revisión de los POT.
} 
Tabla 1. Planes Parciales Adoptados en Ciudades Colombianas a 2007.

\begin{tabular}{|l|r|r|}
\multicolumn{1}{c}{ Ciudad } & No de Planes & \multicolumn{1}{c|}{ Area / Has } \\
\hline Bogotá & 27 & 545 \\
\hline Pereira & 13 & 420,55 \\
\hline Barbosa & 1 & 5 \\
\hline Medellín & 23 & 517,6 \\
\hline Popayan & 2 & 181,54 \\
\hline Sogamoso & 2 & 116 \\
\hline Yopal & 2 & 150,85 \\
\hline Palmira & 5 & 235,13 \\
\hline Barranquilla & 3 & 579 \\
\hline Buenaventura & 1 & 37 \\
\hline Total & $\mathbf{7 9}$ & $\mathbf{2 . 7 8 7 , 6 7}$ \\
\hline
\end{tabular}

Fuente: Encuesta a ciudades. Departamento Nacional de Planeación: DDUPA, 2007.

De otra parte, y pese a que García-Bellido en su artículo destaca que el modelo colombiano supera al español en cuanto a que "la LDT simplifica en un solo tipo de Plan Parcial la gestión del suelo, tanto en suelos urbanos como de expansión (García-Bellido, 1998, p 130)"”; en la práctica su aplicación viene siendo más expedita en los de expansión, y no en los urbanos con tratamientos de desarrollo y renovación urbana. De tal forma, es muy prematuro aún confirmar la supuesta ventaja introducida en el modelo colombiano acerca del alcance multipropósito de los mismos.

De otra parte, y en la medida que la articulación de las dos categorías de espacios urbanos que contienen los Planes Parciales (públicos y privados) debe estar regida por la calidad de vida del entono y darse de forma recíproca, estable, determinada y cierta para cada cultura o nivel de desarrollo social, es importante que el modelo colombiano supere la situación puramente individualista en la que algunos promotores inmobiliarios o propietarios del suelo pretendan siempre adaptar la norma a sus propios intereses con el fin de obtener el mayor aprovechamiento y ocupación del suelo posible. Lo anterior, sin importar la aplicación efectiva de estándares urbanísticos adecuados, relacionados principalmente con los sistemas ecológicos, de movilidad y espacio público.

Al respecto, el Gobierno colombiano expidió un decreto reglamentario de la LDT en materia de Planes Parciales ${ }^{4}$, a través del cual, además de establecer los procedimientos y plazos para su formulación, concertación y adopción, delimitó un escenario para la estimación del reparto de las cargas (generales y locales) y los beneficios. Pese a tales desarrollos reglamentarios, aún es ambiguo por ejemplo la aplicación de estándares como el de espacio público por habitante, el cual desde otro decreto ${ }^{5}$ se determinó como mínimo en 15 metros. Exigencias como esta, derivadas del mismo ejercicio reglamentario de la LDT, no tienen mayor aceptación por parte de los propietarios del suelo a quienes se les exige a manera de carga (obligatoria y gratuita) dichas cesiones. En la Tabla 2 se presentan las áreas de suelo cedidas para espacio público (parques y zonas verdes) a través de Planes Parciales en tres de las principales ciudades del país, las cuales oscilan entre el $13 \%$ y el $18 \%$ del área bruta de los mismos.

\footnotetext{
3 "El modelo español diferencia artificiosamente los nombres de los planes parciales o especiales de múltiples fines, según donde y para lo que se apliquen".

${ }^{4}$ Ministerio de Ambiente, Vivienda y Desarrollo Territorial. Decreto 2181 de 2006.

${ }^{5}$ Ministerio de Ambiente, Vivienda y Desarrollo Territorial. Decreto 1504 de 1998.
} 
Tabla 2. Cesión de suelo para espacio público en planes parciales.

\begin{tabular}{lccc}
\hline \multicolumn{1}{c}{ Ciudad } & $\begin{array}{c}\text { Area Total Planes } \\
\text { Parciales (Has) }\end{array}$ & $\begin{array}{c}\text { Area Cesión } \\
\text { Espacio Público } \\
\text { (Has) }\end{array}$ & $\%$ \\
\hline Bogotá & 545 & 71 & 13 \\
Medellín & 517 & 93 & 18 \\
Barranquilla & 579 & 107 & 18 \\
\hline
\end{tabular}

Fuente: Oficinas de Planeación de las ciudades. Elaboración propia. 2008.

Un obstáculo importante que enfrenta actualmente la implementación de los instrumentos de planeamiento derivado tiene que ver con el exceso de trámites, y consecuentemente los tiempos que requieren ahora los propietarios del suelo o promotores inmobiliarios para desarrollar sus proyectos urbanísticos. Las fases de revisión y adopción por parte de las autoridades municipales competentes (normalmente a través de las oficinas de planeación) se dilatan excesivamente mientras se logran acuerdos y ajustes, especialmente en temas de servicios públicos, medio ambiente y cumplimiento de estándares urbanísticos asociados con la malla vial, el espacio público y los equipamientos. Pese a la eliminación de algunos trámites relacionados con la consulta de los Planes Parciales ante la autoridad ambiental, las demoras en el proceso de adopción persisten y la queja de los particulares se mantiene.

Así mismo, y volviendo al tema de los estándares urbanísticos, no se ha establecido un límite máximo de densidad o intensidad habitacional, o un tope de índice de edificabilidad (por ejemplo, una frontera prudencial como la que propone García-Bellido de 75 - 80 viviendas por hectárea), que permita cerrar el sistema de reparto y especialmente garantizar principios de proporcionalidad equitativa a través de los Planes Parciales. Al respecto, aún está vigente la recomendación de García-Bellido de llevar a un decreto o reglamento un grupo de estándares de reservas de suelo (valores mínimos o franjas mínimas exigibles que debería adoptar los POT) para equipamientos públicos e infraestructuras de servicios públicos.

Sobre la clasificación del suelo, particularmente del suelo de expansión urbana, se viene cumpliendo el anuncio de García-Bellido en cuanto a que en la medida que los propietarios de este suelo tienen asegurada su valoración por la Ley e impiden la invasión de sus terrenos, el suelo restante de borde urbano clasificado como rural va a ser el depositario de las expansiones marginalizadas y clandestinas, en muchos casos con la plena cooperación de sus propietarios quienes con esto revalorizan de facto dicho suelo. Lo anterior puede ser más evidente si no se adoptan medidas de control urbano para evitar o dirigir los procesos de desarrollo espontáneo en las áreas rurales o suburbanas.

Otro aspecto de la clasificación del suelo que vale la pena resaltar tiene que ver con la imprecisión con la que se llevó a cabo la delimitación de la categoría de suelos de protección, tanto por situaciones ambientales como de riesgo, en cualquiera de las tres clases de suelo establecidas por la LDT. Dicha delimitación, en la mayor parte de los casos, se realizó sin el pleno conocimiento de las limitaciones y afectaciones que se generaban sobre el derecho de propiedad, y los usos actuales y potenciales de los predios. Como resultado de lo anterior, se han generado innumerables procesos de consulta y revisión de los POT (no en todos los casos a favor del propietario) entre los propietarios afectados, las autoridades ambientales y los municipios. 


\subsection{Participación de la colectividad en las plusvalías públicas.}

Finalmente, un aspecto que vale la pena mencionar, en la medida que su aplicación garantiza también el cumplimiento de la función social de la propiedad, tiene que ver con la definición e implementación del mecanismo de participación de plusvalías determinado por el capítulo IX (Artículos 73 al 90) de la LDT. Mientras que en España "es un instrumento aún muy mal resuelto y que han padecido onerosamente desde 1975 (García-Bellido, 1998, p 142)"; en Colombia no goza de un avance importante, tanto por no tener resuelta su reglamentación ${ }^{6}$ y consecuentemente por no haberse aplicado, excepto parcialmente en ciudades como Bogotá y Medellín.

Sobre el procedimiento de cálculo, para efectos de aplicar lo establecido por la LDT en el caso de la autorización específica de un "mayor aprovechamiento" del suelo en edificación (Artículo 77), se requiere precisar la fecha de referencia para el establecimiento del valor comercial por metro cuadrado de suelo, como también las formulas para el cálculo del efecto y pago de la participación cuando este es autorizado.

Así mismo, se considera que los trámites establecidos por la Ley para los procedimientos de cálculo, liquidación y cobro de la participación son muy complejos, razón por la cual la mayor parte de las ciudades del país no la han implementado.

\section{Conclusiones.}

Por la riqueza de sus comentarios y la precisión de sus recomendaciones, el artículo de García-Bellido se constituye en un referente importante para medir los avances en la implementación de la LDT colombiana; como también, en un compendio de reflexiones aún vigentes desde las cuales se sigue aportando a su reglamentación e implementación.

Apenas con 10 años de expedición de la LDT, se considera un tiempo muy corto para llevar a cabo una evaluación sobre la "eficacia" de los instrumentos de planeamiento urbanístico general y derivado. No obstante, Colombia evidencia avances importantes tanto en la organización jurídica de su estructura (expedición de la Ley y sus decretos reglamentarios), como en la formulación e implementación de los mismos (particularmente los POT) en todos los municipios del país.

La introducción de la "función pública del urbanismo" dentro del modelo descentralizado de planeamiento económico y social, se ha constituido en uno de los principales aportes que ha realizado la LDT y la implementación de los instrumentos de planeamiento urbanístico. Sin embargo, los municipios y distritos deben realizar un esfuerzo mayor en el cumplimiento de dicho principio, particularmente a través de acciones como el control urbano.

Una vez superada la primera fase de implementación de la LDT, con la respectiva formulación de los POT en casi todos los municipios del país, la segunda fase debe concentrarse en terminar de definir los escenarios técnico-políticos y jurídico-económicos del planeamiento derivado a través de los Planes Parciales y las UAU. Al respecto, es importante terminar de precisar, conceptual y técnicamente, el escenario de la distribución equitativa de cargas y beneficios entre los partícipes de la gestión urbanística.

\footnotetext{
${ }^{6}$ El Decreto 1599 de 1998 reglamentó la participación en plusvalías, el cual fue derogado posteriormente por el Decreto 2320 de 2000.
} 
Así mismo, debe trabajarse aún más en el forjamiento de una "cultura urbanística" que garantice la confianza de los propietarios del suelo y el sector privado en el proceso de gestión asociada; como también, la aprensión de los principios del ordenamiento territorial establecidos por la LTD: función social y ecológica de la propiedad, distribución equitativa de cargas y beneficios, y prevalencia del interés general sobre el particular.

Para cumplir con lo anterior, las entidades del Gobierno Nacional deben mantener y profundizar los ejercicios de "pedagogía de la Ley" y la "asistencia técnica" a las entidades territoriales. Lo anterior, con el fin de garantizar la comprensión y alcances de la fase de planeamiento derivado, y la efectiva aplicación de los instrumentos de financiación (participación en plusvalías) y de los sistemas de gestión asociada (reajuste, integración, cooperación y compensación).

Para efectos de desenredar el proceso de formulación y adopción de los instrumentos de planeamiento urbanístico derivado (Planes Parciales y UAU) se requiere acometer acciones (jurídicas y metodológicas) de simplificación de los trámites y tributos asociados con los mismos. De igual forma, es importante que los equipos locales de planeación se fortalezcan técnicamente y mejoren su capacidad de gestión.

\section{Bibliografía.}

García-Bellido, Javier. Ministerio de Desarrollo Económico, Centro de Estudios de la Construcción y el Desarrollo Urbano y Regional - CENAC. Revista Desarrollo Urbano en Cifras, $1998, N^{\circ} 5$, p.118-194.

\section{Legislación Consultada.}

Diario oficial. Ley de Reforma Urbana, 9ª de 1989.

Presidencia de la República. Constitución Política de Colombia de 1991.

Ministerio de Desarrollo Económico. Ley de Desarrollo Territorial, 388 de 1997.

Ministerio de Desarrollo Económico. Decreto 1599 de 1998. Por el cual se reglamentan las disposiciones referentes a la participación en plusvalías de que trata la Ley 388 de 1997.

Ministerio de Ambiente, Vivienda y Desarrollo Territorial. Decreto 2181 de 2006. Por el cual se reglamentan parcialmente las disposiciones relativas a planes parciales contenidas en la Ley 388 de 1997 y se dictan otras disposiciones en materia urbanística.

Ministerio de Ambiente, Vivienda y Desarrollo Territorial. Decreto 1504 de 1998. Por el cual se reglamenta el manejo del espacio público en los planes de ordenamiento territorial.

Ministerio de Ambiente, Vivienda y Desarrollo Territorial. Decreto 2320 de 2000. Por el cual se deroga el Decreto 1507 de 1998. 
Architecture, City, and Environment

Arquitectura, Ciudad y Entorno 